\title{
An analysis of the trade balance for OECD countries using periodic integration and cointegration.
}

February 20, 2014

\begin{abstract}
We analyze imbalances in external accounts that have historically affected most developed countries. The purpose of this study is to shed some light on the sustainability of the current account for a group of OECD countries by merging the popular Husted (1992) testing procedure with recent econometric analysis dealing with seasonality. A necessary condition for current account sustainability is that exports and imports are cointegrated. Following previous empirical studies (Husted (1992), Arize (2002) and Hamori (2009)) we analyze the long-run relationship linking exports and imports, using quarterly data. In contrast to these studies, we explicitly deal with seasonal effects through the use of periodic integration and cointegration and find a long-run relationship for the majority of the countries.
\end{abstract}

Keywords: Current account, time series, periodic integration, periodic cointegration,

JEL codes: F14, F32, C22

\section{Motivation}

Since the beginning of the 70s, external imbalances have been widening considerably in the world economy. Economic globalization has meant an increase in international trade and capital mobility facilitating the financing of larger and more persistent disequilibria. Among the OECD countries there is a clear trend toward larger external imbalances (IMF, 2005). The relevance of the disequilibrium in the external balances during the last decade has renewed the academic interest for this issue. Gourinchas and Rey (2007) have decomposed the external adjustment into a financial (valuation) channel and a trade (net export) channel and show that the deterioration in net exports or net foreign asset position of a country have to be matched either by future net export growth (trade adjustment channel) or by future increases in the returns of net foreign asset portfolio (financial adjustment channel). The valuation channel is important in the medium-term whereas the net export channel matters in a long-time horizon. This paper analyzes imbalances in external accounts in the long-run from the traditional trade balance approach that postulates the trade channel as the main external adjustment mechanism. For this reason, the variables of interest are exports and imports of the countries analyzed.

Some previous empirical studies, such as Husted (1992), Arize (2002) and, more recently, Hamori (2009) have dealt with the long-run relationship between exports and imports using the cointegration methodology. Although the majority of the empirical evidence is based on annual or quarterly data and the latter can be affected by seasonal effects, to the best of our knowledge, the empirical literature has neglected the presence 
of seasonal non-stationary components. However, since the seminal work of Gupta (1964) it is a well documented fact the major importance of seasonality in exports and imports time series.

The existence of seasonal products poses some significant challenges for the scholars. According to IMF (2004) seasonal commodities are products that are either not available in the marketplace during certain seasons of the year or are available throughout the year but there are regular fluctuations in prices or quantities that are synchronized with the season of the time of the year. A commodity that satisfies the first condition is termed a "strongly seasonal" commodity, whereas a commodity that satisfies the second one will be called a "weakly seasonal". These terms coincide with the distinction between "narrow" and "wide" seasonal products made earlier by Balk (1980) or the taxonomic classification between "type 1" and "type 2" seasonality proposed in Diewert (1998).

According to Mitchell (1927) there are two main sources of seasonal fluctuations in prices and quantities that may cause fluctuations in the demand or supply for many products and consequently in trade flows: climate and custom. The importance of seasonality has been assessed by Alterman et al. (1999) quantifying that for a typical country, seasonal purchases will often amount to one-fifth to one-third of all consumer purchases.

Nevertheless, seasonality is a phenomenon that has not received sufficient attention in the economic literature in general. The standard treatment is either to assume that the seasonality that appears in the time series is deterministic or, alternatively, to use a method to remove the seasonal component of the variables and estimate the models using seasonally-adjusted variables.

Ghysels (1990), Ghysels and Perron (1993) and del Barrio Castro et al (2002) show that the removal of seasonality with X-11 and SEATS standard procedures introduces excessive persistence in the series, which reduces the power of unit root tests. Maravall (1993) shows how seasonal adjustment procedures induce non invertible moving average processes in the filtered series, invalidating the inference made in most of the unit root and cointegration tests.

Researchers confronted with nonstationary seasonal time series have two alternatives methods to deal with non-stationary seasonality: Seasonal Integration $(S I)$ (Hylleberg, 1990, Hylleberg et al, 1995, Rodrigues and Taylor 2007, Kunst (2009) $)^{1}$ and/or Periodic Integration (PI). As argued by Gersovitz and McKinnon (1978), Osborn (1988) and Hansen and Sargent (1993), Periodic Integration is more attractive than Seasonal Integration because PI can arise naturally from the application of economic theory when the underlying economic driving forces, such as preferences or technologies, vary seasonally. Secondly, according to Osborn (1991) and Franses (1994), from an econometric perspective, $P I$ is attractive because it implies that the seasons of the year are cointegrated with each other and hence ensures that the patterns associated with the various seasons are linked in the long-run.

Based on the previous argument, in this paper we intend to use a seasonal treatment that includes periodic autoregressive models as well as periodic integration tests (Boswijk and Franses 1996, del Barrio Castro and Osborn, 2010) to determine the type of seasonality present in the non-stationary series analyzed. As shown in Ghysels and Osborn (2001), this point is crucial as it determines the type of cointegration between the set of variables analyzed. Specifically, if the series are seasonally integrated, longterm relationships can occur at each frequency, that is, "seasonal cointegration", (Lee, 1992 and Johansen and Schaumburg, 1999) or between the seasons of the time series,

\footnotetext{
${ }^{1}$ See also Kunst (1997) and Osborn, Chui, Smith and Birchenhall (1988) for altermative methods of testing for seasonal unit roots .
} 
namely "periodic cointegration" (Boswijk and Franses, 1995). However, if the series are periodically integrated, they can only be periodically cointegrated (del Barrio Castro and Osborn 2008). Moreover, if one does not take into account all the above-mentioned possibilities and ignores the univariate properties of the series analyzed, it may originate problems of spurious correlations and unstable parametrization.

Therefore, in this paper the econometric analysis consists of first determining the order of integration of the trade flows and then, if nonstationary, to test and estimate the existence of a long-run relationship between a country's exports and imports. The countries in our sample are Australia, Canada, Denmark, Sweden, the United Kingdom, Norway, Switzerland and Japan. Those are the OECD countries with non-seasonally adjusted quarterly data that were available. We have excluded France, Italy, the Netherlands, Finland and Spain, the five EMU members in the group, due to the presence of a structural change around $1999^{2}$.

The rest of the paper is organized as follows. Section 2 briefly presents the theoretical background while section 3 reports the econometric tests and the empirical results. Section 4 contains the conclusions.

\section{Theoretical model}

In this paper we follow Husted (1992) who presents a simple theoretical model of a small open economy with no government where there is a representative consumer. This economy produces and exports a composite good. The consumer can borrow and lend in the international markets using one-period instruments. His resources are output and profits from firms that are used for consumption and savings. The consumer's budget constraint in the current period is:

$$
C_{0}=Y_{0}+B_{0}-I_{0}-\left(1+r_{0}\right) B_{-1}
$$

where $C_{0}$ is current consumption; $Y_{0}$ is output, $I_{0}$ is investment, $r_{0}$ is the one period world interest rate, $B_{0}$ is international borrowing that can be positive or negative, whereas $\left(1+r_{0}\right) B_{-1}$ is the stock of debt by the agent (or the country's external debt). The budget constraint must hold for every period and the usual transversality condition should be fulfilled. As expression (1) should hold for every period, this constraint can be combined to formulate an intertemporal budget constraint, such as:

$$
B_{0}=\sum_{t=1}^{\infty} \mu_{t} T A_{t}+\lim _{n \rightarrow \infty} \mu_{t} B_{n}
$$

where $T A_{t}=X_{t}-M_{t}\left(=Y_{t}-C_{t}-I_{t}\right)$ is the trade balance in period $t$, that is, income minus absorption; $X_{t}$ are the exports and $M_{t}$ are imports, whereas $\mu_{t}$ is the discount factor.

Husted (1992) arrives to a testable equation that relates exports with imports inclusive of interest payments on net debt:

$$
X_{t}=a+b^{*} M M_{t}+e_{t}
$$

where $M M_{t}=M_{t}+r_{t} B_{t-1}$. Under the null hypothesis that the economy satisfies

\footnotetext{
${ }^{2}$ The presence of a level shift recommends the use of unit root tests that explicitly allow for it in the alternative hypothesis. This will be the object of future research.
} 
its intertemporal budget constraint, we expect $b=1$ and $e_{t}$ is stationary. Thus, if both variables are $\mathrm{I}(1)$, under the null, they are cointegrated, with a cointegrating vector $(1,-1)$.

We assume that the world interest rate is stationary. Therefore, the term $r_{t} B_{t-1}$ would also be stationary. In practice, we can test for cointegration between exports and imports when we believe that the adjustment works essentially through the trade channel.

\section{Econometric techniques}

In order to explicitly acknowledge the role of seasonality, it is often convenient to represent a univariate time series as $y_{s \tau}$, where the first subscript refers to the season $(s)$ and the second subscript to the year $(\tau)$, as we have quarterly data $s=1,2,3,4$. For simplicity of exposition, we assume that data are available for precisely $N$ years, so that the total sample size is $T=4 N$. Note that, throughout the paper, it is understood that $y_{s-k, \tau}=y_{4-s+k, \tau-1}$ for $s-k \leq 0$.

Applications of periodic processes within economics have focused on the autoregressive case, with the $p^{\text {th }}$ order periodic autoregressive, or $P A R(p)$ process, defined by

$$
y_{s \tau}=\alpha_{s}+\phi_{1 s} y_{s-1, \tau}+\phi_{2 s} y_{s-2, \tau}+\cdots+\phi_{p s} y_{s-p, \tau}+e_{s \tau}, \quad s=1,2,3,4
$$

where $e_{s \tau}$ is white noise. In (4) we only consider seasonal intercepts $\alpha_{s}$ due to the nature of the analyzed data, that are ratios. Note that all the coefficients in this process may vary over seasons $s=1, \ldots, 4$. The conventional (nonperiodic) $A R(p)$ process is a special case with $\phi_{i s}=\phi_{i}(s=1,2,3,4)$ for all $i=1,2, \ldots, p$. However, in the presence of seasonality, it is important to consider the possibility that the process may be periodic, with at least some $A R$ coefficients in (4) varying over the year.

Under the assumption that $y_{s \tau}$ is integrated of order 1 , and using a similar notation to Boswijk and Franses (1996), (4) can also be written as

$$
\begin{aligned}
\left(y_{s \tau}-\varphi_{s} y_{s-1, \tau}\right)= & \alpha_{s}^{*}+\psi_{1 s}\left(y_{s-1, \tau}-\varphi_{s-1} y_{s-2, \tau}\right)+\cdots+ \\
& +\psi_{p-1, s}\left(y_{s-p+1, \tau}-\varphi_{s-p+1} y_{s-p, \tau}\right)+e_{s \tau}
\end{aligned}
$$

where $\prod_{s=1}^{4} \varphi_{s}=1^{3}$ with the quasi-difference $y_{s \tau}-\varphi_{s} y_{s-1, \tau}$ being stationary. Boswijk and Franses (1996) analyze the distribution of the Likelihood Ratio test statistic for the null of periodic integration $\prod_{s=1}^{S} \varphi_{s}=1$ in (5), with this statistic defined by

$$
L R_{P I}=T \ln \left(\frac{R S S_{0}}{R S S_{1}}\right)
$$

where $R S S_{0}$ and $R S S_{1}$ denote the residual sum of squares under the null hypothesis and from the unrestricted form (4), respectively. Under the null hypothesis of a $P I(1)$ process, they show that this statistic has the same asymptotic distribution as the squared Dickey-Fuller $t$-statistic for a conventional (nonperiodic) $I(1)$ process.

To implement the previous test (6) we need to determine the order $p$ for the unrestricted and restricted models (4) and (5). To do that we follow Franses and Paap $(1994,2004)$ and use the Schwarz criterion in conjunction with diagnostic tests for neglected periodic serial correlation to determine $p$ with a maximum value of 5 . Franses

\footnotetext{
${ }^{3}$ See Ghysels and Osborn (2001, pp. 153-155) for details about the models nested in $(4) /(5$.
} 
and Boswijk (1997) also proposed a F-type statistic $F_{\text {per }}$ to test the null of non periodic variation in the coefficients of (4) $H_{0}: \phi_{j s}=\phi_{j}$ for $j=1, \cdots p$. The implementation of the $L R_{P I}$ Boswijk and Franses test by practitioners has two problems, in first place, the models (4) and (5) tend to have a large number of parameters, and in second place, to fit model (5) we will need non-linear methods of estimation. Recently del Barrio Castro and Osborn (2011) have proposed two non-parametric tests (based on the Breitung (2002) and Stock (1999) unit root tests) that allow us to circumvent the limitations of the Boswijk and Franses (1996) test. They propose to compute a variance ratio statistic for a given season $s$ as

$$
V R T_{s}=N^{-2} \frac{\sum_{\tau=1}^{N} \hat{U}_{s \tau}^{2}}{\sum_{\tau=1}^{N} \hat{u}_{s \tau}^{2}} \quad s=1, \ldots, 4
$$

where $\hat{U}_{s \tau}$ is the season-specific partial sum $\hat{u}_{s 1}+\hat{u}_{s 2}+\cdots+\hat{u}_{s \tau}$, with $\hat{u}_{s \tau}$ obtained as the OLS residuals $\hat{u}_{s \tau}=y_{s \tau}-\widehat{\boldsymbol{\beta}}_{s}^{\prime} \mathbf{z}_{\tau}$ from a regression of observations for season $s, y_{s \tau}$ $(\tau=1, \ldots, N)$, on $\mathbf{z}_{\tau}$ that collects the deterministic part, in our case $\mathbf{z}_{\tau}=1$. In order to test the $P I(1) / I(1)$ null hypothesis, they use the average variance ratio statistic

$$
V R T_{P I}=4^{-1} \sum_{s=1}^{4} V R T_{s}
$$

where each $V R_{s}$ is defined in (7).

Additionally, based on Perron and Ng (1996) and Stock (1999) del Barrio Castro and Osborn (2011) propose to apply for a single season $s$, the corresponding season-specific $M S B$ test statistic is:

$$
M S B_{s}=\left(\frac{N^{-2} \sum_{\tau=1}^{N} \hat{u}_{s, \tau-1}^{2}}{\widehat{\gamma}_{s l}}\right)^{\frac{1}{2}} \quad s=1, \ldots, 4
$$

which requires an appropriate long-run variance estimator $\widehat{\gamma}_{s l}$ for the annual difference $\Delta u_{s \tau}=u_{s \tau}-u_{s, \tau-1}$ relating to season $s$. $\widehat{\gamma}_{s l}$ is obtained based on sample autocovariances using the Bartlet and quadratic spectral kernels, following Newey and West (1994, equations (3.8) to (3.15) and Table 1) data-dependent bandwidth procedure.

As in the previous case they propose the use of the average $M S B_{P I}$ statistic

$$
M S B_{P I}=4^{-1} \sum_{s=1}^{4} M S B_{s} .
$$

del Barrio Castro and Osborn (2011) show that the $V R T_{P I}$ (8) and $M S B_{P I}$ (10) tests under the null of periodic integration $\prod_{s=1}^{4} \varphi_{s}=1$ (8) have the same distribution of the variance ratio test proposed by Breitung (2003) in the case of $V R T_{P I}$ (8) and of the modified Sargan-Bhargava test proposed by Stock (1999) in the case $M S B_{P I}$ (10).

As mentioned in Section 1 above, Osborn (1991) and Franses (1991) show that the main characteristic of a periodically integrated process is that the nonstationary behaviour is caused by a common stochastic trend shared by the quarters of the time series. Based on that Franses (1994) and del Barrio Castro and Osborn (2012) proposed the use of the Johansen (1988) and the Breitung (2002) procedures respectively to determine the number of cointegration relationship (common trends) between the quarters (seasons) of 
the time series ${ }^{4}$. The results of a small monte carlo experiment (available upon request) show that the Johansen procedure when applied to quarterly PI processes with sample between 30 and 50 years (as in our case) is able to determine the presence of cointegration relationship between the quarters but is unable to determine whether there are 3 cointegration relationship between the quarters. This same situation was reported by del Barrio Castro and Osborn (2012) for the Breitung cointegration tests.

As shown by Ghysels and Osborn (2001, pp.168-171) and del Barrio Castro and Osborn (2008), when the series follow $P I$ processes, the only cointegration possibilities are periodic cointegration or nonperiodic cointegration, with cointegration for any one season implying cointegration for all seasons, that is, full cointegration. They also show that in order to have full nonperiodic cointegration (equivalent here to conventional cointegration) the involved processes must share the same $\varphi_{s}$ coefficients in (5). Hence if two variables are cointegrated with a $(1,-1)$ vector both processes must share the same $\varphi_{s}$ coefficients in (5). Thus, the $L R_{P I}, M S B_{P I}$ and $V R T_{P I}$ tests can be applied to the difference between two variables.

Finally, del Barrio Castro and Osborn (2008) propose a residual-based Likelihood Ratio test $\left(L R_{C R}\right)$ for the null of not full periodic cointegration between periodically integrated processes and obtain their asymptotic distribution, in particular they show that the $L R_{C R}$ statistics follow the squared distribution reported by Phillips and Ouliaris (1988) for the residual based ADF cointegration test. This test is based on testing the null of periodic integration in the residuals of the following model (in the case of two variables $y_{s \tau}$ and $x_{s \tau}$ ):

$$
y_{s \tau}=\alpha_{s}+\beta_{s} x_{s \tau}+u_{s \tau} \quad s=1,2,3,4
$$

Under the null of non full periodic cointegration del Barrio Castro and Osborn (2008) show (see Lemma 4 ) that the residuals $\hat{u}_{s \tau}$ of (11) asymptotically retain the same nonstationary periodic coefficients of the univariate process for $y_{s \tau}$. Hence the strategy is to test for periodic integration in the residuals $\hat{u}_{s \tau}$ using the unrestricted model:

$$
\hat{u}_{s \tau}=\sum_{j=1}^{p^{*}} \phi_{j s}^{*} \hat{u}_{s-j, \tau}+\varepsilon_{s \tau} \quad s=1,2,3,4
$$

with residual sum of squares $\mathbf{R S S}_{1}$. And the restricted model:

$$
\hat{u}_{s \tau}=\varphi_{s}^{*} \hat{u}_{s-1, \tau}+\sum_{j=1}^{p^{*}-1} \psi_{j s}^{*}\left(\hat{u}_{s-j, \tau}-\varphi_{s-1 \hat{u} s-j-1, \tau}^{*}\right)+\varepsilon_{s \tau}
$$

subject to $\varphi_{1}^{*} \varphi_{2}^{*} \varphi_{3}^{*} \varphi_{4}^{*}=1$, with residual sum of squares $\mathbf{R S S}_{0}$. Finally the $L R_{C R}$ to the test the null of non full periodic cointegration has the expression:

$$
L R_{C R}=T \ln \left(\frac{\mathbf{R S S}_{0}}{\mathbf{R S S}_{1}}\right) .
$$

\section{Empirical results}

As in Azire (2002) we analyze the natural logarithms of the nominal ratio exports to GDP $(\ln (\exp / g d p)$ hereafter $)$ and imports to GDP $(\ln (i m p / g d p))$. We have collected

\footnotetext{
${ }^{4}$ We have not applied these procedures to our data because these methods perform well in this context for sample sizes of around 75 years in the case of the Johansen tests and 100 years in the case of the Breitung tests.
} 
quarterly data (not seasonally adjusted) for the following non-Eurozone countries: Australia, Canada, Denmark, Sweden, United Kingdom, Norway, Switzerland and Japan. The evolution of the ratios is depicted in graphs 1 and 2. The sample ends in 2009Q1 for all the countries considered, but it has different starting dates: 1960Q1 for Australia, 1961Q1 for the UK, 1977Q1 for Canada, 1978Q1 for Denmark and finally 1980Q1 for the remaining countries.

From the graphs we can observe that the ratios $\ln (\exp / g d p)$ and $\ln (i m p / g d p)$ show clear seasonal variation but not very large seasonal oscillations. Note also that from the evolution of the time series we do not observe a trending behavior in our data (with the exception of some weak evidence in the cases of Canada and Sweden). Hence we consider only seasonal dummies in the deterministic part.

Taking into account the previous arguments and the evolution of the ratios $\ln (\exp / g d p)$ and $\ln (i m p / g d p)$ for each country (graphs 1 and 2), we focus on periodic integration as the potential source of non-stationarity in our data.

The results obtained for the unit root tests described in the previous section are reported in table1. The first column corresponds to the $F_{\text {per }}$ test, the second to Boswijk and Franses (1996) $L R_{P I}$ or Likelihood Ratio test, followed by the order of the fitted $P A R(p)$ for each time series. $M S B_{P I}^{b}$ and $M S B_{P I}^{q}$ denote the statistic $M S B_{P I}$ with the Bartlet and quadratic spectral kernels, respectively. Finally, we present the results of $V R T_{P I}$, that is, del Barrio Castro and Osborn (2011) variance ratio test. For each country we also report the results for the difference between $\ln (\exp / g d p)$ and $\ln (i m p / g d p)$.

From the results of the $F_{p e r}$ test we find clear evidence of periodicity in both $\ln (\exp / g d p)$ and $\ln (\mathrm{imp} / g d p)$ for the majority of the countries. Exceptions are the cases of Norway for $\ln (\exp / g d p)$ and Switzerland and Japan for $\ln (i m p / g d p)$. We cannot reject the null of periodic integration using any of the tests $\left(L R_{P I}, M S B_{P I}\right.$ and $\left.V R T_{P I}\right)$ for Canada, Sweden and Japan. In the case of Australia we do not reject the existence of periodic integration with the $M S B_{P I}$ and $V R T_{P I}$ tests. Concerning the $L R_{P I}$ test, we do not reject the null of periodic integration for $\ln (\mathrm{imp} / g d p)$ but we do reject it using the $L R_{P I}$ test for $\ln (\exp / g d p)$. For Denmark we only reject the null of periodic integration with the $L R_{P I}$ test for $\ln (i m p / g d p)$. In the UK the null is rejected for $\ln (i m p / g d p)$ at the $10 \%$ for the $L R_{P I}$ and the $M S B_{P I}$ tests. For Norwegian variables we only reject the null with the $M S B_{P I}$ tests at $10 \%$ for $\ln (\exp / g d p)$. Finally, in the case of Switzerland the null is rejected with the $V R T_{P I}$ test for $\ln (\exp / g d p)$ at $10 \%$ level of significance and for $\ln (\exp / g d p)$ at a $5 \%$ level in the case $V R T_{P I}$ test and at a $10 \%$ level for the $M S B_{P I}$ tests. Overall we can conclude that we have found reasonable empirical evidence in favour of the hypothesis that the two ratios follow periodically integrated processes for all the countries. In order to take into account the weak trending behaviour found in the cases of Canada and Sweden for $\ln (\exp / g d p)$ and $\ln (i m p / g d p)$, we have computed the periodic integration tests including seasonal dummies and trends. The results are that we do not reject the null of periodic integration in none of the cases ${ }^{5}$.

As shown by Ghysels and Osborn (2001, pp.168-171) and del Barrio Castro and Osborn (2008), when the series follow PI processes, the only cointegration possibilities are periodic cointegration or nonperiodic cointegration, with cointegration for any one season implying cointegration for all seasons, that is, full cointegration. They also show that in order to have full nonperiodic cointegration the involved processes must share the same $\varphi_{s}$ coefficients in (5). Note that full nonperiodic cointegration is equivalent to conventional cointegration. Hence if $\ln (\exp / g d p)$ and $\ln (\mathrm{imp} / \mathrm{gdp})$ are cointegrated with

\footnotetext{
${ }^{5}$ The role played by intercepts and trends in periodically integrated processes is more complicated than in the case of standard integrated processes. For an in-depth analysis of this, see Paap and Franses (1999).
} 
a $(1,-1)$ vector both processes must share the same $\varphi_{s}$ coefficients in (5). We report these coefficients in table 2 , including all the time series for all the countries in our sample. We also report in table 1 (see the last row for each country) the results obtained for the $L R_{P I}, M S B_{P I}$ and $V R T_{P I}$ when applied to the difference between $\ln (\exp / g d p)$ and $\ln (i m p / g d p)$, denoted as difln. The results about the residual based Likelihood Ratio Test proposed by del Barrio Castro and Osborn (2008) are also reported in table 2 .

In the case of Australia, Canada and the UK we find clear evidence of cointegration with a $(1,-1)$ vector. Note that the coefficients for $\ln (\exp / g d p)$ and $\ln (\mathrm{imp} / g d p)$ in table 2 are quite similar. Moreover, applying the $L R_{C R}$ test we also find evidence of full periodic cointegration as expected. In the case of Norway there is no $(1,-1)$ cointegration but we detect full nonperiodic cointegration at a $10 \%$ level. Also note that in this case the $\varphi_{s}$ coefficients are quite different. For Japan we find weak evidence of $(1,-1)$ cointegration (at $10 \%$ with the $L R_{P I}$ test), but strong full periodic cointegration with the $L R_{C R}$ test. Finally for Denmark, Sweden and Switzerland we do not find nonperiodic cointegration with vector $(1,-1)$ nor full periodic cointegration.

\section{Concluding remarks.}

The issue of external imbalances has regained interest in the last years due to the impact of the international financial crisis. In this paper, we assess whether the trade channel, as an adjustment mechanism in the long-run, has been working as postulated by the theory. The contribution of the paper to previous literature is twofold. First, from an econometric point of view, we refine previous analysis considering the seasonal components of the variables involved. This is not trivial because seasonality is important in exports and imports and should be addressed to guarantee a robust empirical analysis. Second, we obtain more evidence in favour of cointegration than in previous studies, which has important consequences from an economic policy view. In a well-functioning economy, deficits are temporary phenomena that will be balanced by future surpluses but in a country with distorted markets there is no tendency towards balance of payments equilibrium, and thus sustained external imbalances may reflect the implementation of a bad economic policy or just "bubble-financing".

Therefore we analyze the long-run relationship linking exports and imports for a group of developed countries between 1960/1970 and 2009 using quarterly data nonadjusted for seasonality. As many official statistical offices only provide information of seasonaly-adjusted data, we are restricted to twelve countries and different data spans: Australia, Canada, Denmark, France, Finland, Italy, Japan, the Netherlands, Norway, Spain, Switzerland, Sweden and UK. We have finally excluded the five EMU members due to the presence of a clear level shift in 1999.

In the empirical literature, the issue of seasonal non-stationary components has been frequently neglected. Thus, the aim of the paper is to apply a flexible approach to cointegration, where we allow for the presence of these type of non-stationary components (instead of deterministic seasonality).

The general conclusion of the univariate analysis is that both exports and imports ratios over GDP are periodically integrated processes for all the countries. Consequently, the only cointegration possibilities are periodic cointegration or nonperiodic cointegration, with cointegration for any one season implying cointegration for all seasons (i.e. full cointegration). Using a residual based $L R_{C R}$ test proposed by del Barrio Castro and Osborn (2008) for the null hypothesis of non full periodic cointegration, we conclude that we find either full periodic cointegration, such as in the cases of Canada, the UK and 
Australia, or full nonperiodic cointegration, as in Norway and Japan. However, neither nonperiodic nor full periodic cointegration is found for Denmark, Sweden and Switzerland signalling the existentence of persistent disequilibria and the need of prospective adjustments. These three countries are European, two of them EU members. This last result may be the consequence of the close commercial link between them and the Eurozone which has been affected by a progressive increase of financial integration among EU members (singularly important for euroarea members). The consequence has been an improvement in the financial conditions of EU countries and a widening of external disequilibria among them (i.e. persistent surpluses in the case of Denmark and Sweden) that has only been corrected from 2007. Moreover, the case of Switzerland presents peculiarities related to the importance of the financial sector in the economy and its capacity for permanent financing of its external imbalances.

\section{References}

[1] Abeysinghe, T. (1994). "Deterministic Seasonal Models and Spurious Regressions." Journal of Econometrics, 61(2): 259-272.

[2] Alterman, W.F., W. E. Diewert, and R. C.Feenstra. (1999). International Trade Price Indexes and Seasonal Commodities (Washington: Bureau of Labor Statistics).

[3] Arize, A.C. (2002): "Imports and exports in 50 countries. Tests of cointegration and structural breaks", International Review of Economics and Finance, vol. 11, pp. 101-115.

[4] Balk, B. M. (1980). 1980c, "A Method for Constructing Price Indices for Seasonal Commodities," Journal of the Royal Statistical Society, Series A, Vol. 143, 68-75.

[5] Boswijk, H.P. and P.H. Franses (1995), Periodic cointegration: representation and inference, Review of Economics and Statistics, 77, 436-454.

[6] Boswijk H.P. and P.H. Franses (1996) Unit roots in periodic autoregressions, Journal of Time Series Analysis 17, 221-245.

[7] Breitung J.(2002) Nonparametric tests for unit roots and cointegration, Journal of Econometrics, 108, 343-363.

[8] del Barrio Castro T., E. Pons and J.Suriñach (2002) The Effects of Working with Seasonal Adjusted Data when Testing for Unit Roots. Economics Letters, 75, 249256.

[9] del Barrio Castro T. and D.R. Osborn (2012) Non-parametric testing for seasonally and periodically integrated processes, Journal of Time Series Analysis, 33 424-437.

[10] del Barrio Castro T. and D.R. Osborn (2011) Nonparametric Tests for Periodic Integration, Journal of Time Series Econometrics, 3(1), Article 4

[11] del Barrio Castro T. and D.R. Osborn (2008) Cointegration For Periodically Integrated Processes, Econometric Theory, 24(1), 109-142

[12] Diewert, W. E. (1998) "High Inflation, Seasonal Commodities and Annual Index Numbers," Macroeconomic Dynamics, Vol. 2, 456-471. 
[13] Franses, P.H. (1994) A Multivariate Approach to modeling univariate seasonal time series, Journal of Econometrics, 63, 133-151.

[14] Franses, P.H. and R. Paap (1994) Model Selection in Periodic Autoregression, Oxford Bulletin of Economics and Statistics, 56, 421-440.

[15] Franses, P.H. and R. Paap (2004) Periodic Time Series Models. Oxford University Press.

[16] Fountas, S. and J.-L. Wu (1999): "Are The U.S. Current Account Deficits Really Sustainable?," International Economic Journal, Korean International Economic Association, vol. 13(3), pages 51-58.

[17] Gersovitz M. and J.G. McKinnon (1978) Seasonality in regression: An application of smoothness priors, Journal of the American Statistical Association, 73, 264-273.

[18] Ghysels, E. (1990). "Unit-Root Tests and the Statistical Pitfalls of Seasonal Adjustment: The Case of U.S. Postwar Real Gross National Product." Journal of Business and Economic Statistics, 8(2): 145-152.

[19] Ghysels E. and P. Perron (1993), The Effect of Seasonal Adjustment Filters on Tests for Unit Roots, Journal of Econometrics, 55, 57-99.

[20] Ghysels E. and D.R. Osborn (2001) The Econometric Analysis of Seasonal Time Series. Cambridge University Press.

[21] Gourinchas, P. O. and H. Rey (2007) "International Financial Adjustment", Journal of Political Economy, 115, (4), 665-703.

[22] Gupta, J.B. (1965) "Seasonality in World Financial and Trade Data", IMF Staff Papers, 12, 353-364.

[23] Hakkio, C. S. and Rush, M. (1991): "Is the Budget Deficit "Too Large?"," Economic Inquiry, Oxford University Press, vol. 29(3), pp. 429-45, July.

[24] Hamori, S. (2009): "The sustainability of trade accounts of the G-7 countries", Applied Economics Letters, vol. 16, 1691-1694.

[25] Hansen L.P. and T.J. Sargent (1993) Seasonality and approximation errors in rational expectation models, Journal of Econometrics, 55, 21-56.

[26] Herzer, D. and F. Nowak-Lehmann (2006): "Is there a long-run relationship between exports and imports in Chile?", Applied Economics Letters, vol. 13, 981-986.

[27] Husted, S. (1992): "The Emerging U.S. Current Account Deficit in the 1980s: A Cointegration Analysis", The Review of Economics and Statistics, vol. 74(1), pp. 159-166. The MIT Press.

[28] Hylleberg, S. (1995). "Tests for Seasonal Unit Roots: General to Specific or Specific to General?" Journal of Econometrics, 69(1): 5-25.

[29] Hylleberg, S., R. Engle, C. W. J. Granger and B. S. Yoo (1990). "Seasonal Integration and Co-Integration." Journal of Econometrics, 44(1-2): 215-238.

[30] IMF (2004). "Treatment of Seasonal Products", in Producer Price Index Manual, ch. 22. IMF. Washington. 
[31] IMF (2005): "Globalization and external imbalances", World Economic Outlook, Chapter III, Washington.

[32] Irandoust, M. and B. Sjoo (2000): "The Behavior of the Current Account in Response to Unobservable and Observable Shocks", International Economic Journal, vol. 14(4), pp. 41-57.

[33] Irandoust, M. and J. Ericsson (2004): "Are imports and exports cointegrated? An international comparison", Metroeconomica, vol. 55(1), pp.49-64.

[34] Johansen S. (1988) Statistical Analysis of Cointegration Vectors, Journal of Economics Dynamics and Control,12, 231-254.

[35] Johansen, S. and E. Schaumburg (1998): "Likelihood analysis of seasonal cointegration," Journal of Econometrics, vol. 88(2), pp. 301-339.

[36] Kunst, R. (2009) "A Nonparametric Test for Seasonal Unit Roots" Economic Series 233, Institute for Advanced Studies.

[37] Kunst, R. (1997) "Testing for Cyclical Non-Stationarity in Autoregressive Processes", Journal of Time Series Analysis, 18, 123-135.

[38] Lee, H. S. (1992). "Maximum Likelihood Inference on Cointegration and Seasonal Cointegration." Journal of Econometrics, 54(1-3): 1-47.

[39] Maravall, A. (1993), Stochastic Linear Trends, Journal of Econometrics, 56, 5-37.

[40] Mitchell, W.C., 1927, Business Cycles (New York: National Bureau of Economic Research).

[41] Narayan, P.K. and S. Narayan (2005): "Are exports and imports cointegrated? Evidence from 22 least developed countries", Applied Economics Letters, vol. 12(6), pp. $375-378$.

[42] Newey W.K. and K.D. West (1994) Automatic lag selection in covariance matrix estimation, Review of Economic Studies, 61, 631-653.

[43] Olekalns, N. (1994). "Testing for Unit Roots in Seasonally Adjusted Data." Economic Letters, 45(3): 273-279.

[44] Osborn, D.R. (1988) Seasonality and habit persistence in a life-cycle model of consumption, Journal of Applied Econometrics, 3, 255-266.

[45] Osborn, D. R., Chui. P. L., Smith, J. P. and Birchenhall, C. R. (1988) "Seasonality and the Order of Integration for Consumption", Oxford Bulletin of Economics and Statistics, 50, 361-377.

[46] Paap R. and P.H. Franses (1999).On Trends and Constants in Periodic Integration, Econometric Reviews, 18, 271-286.

[47] Ramos, F.F.R. (2001): "Exports, imports, and economic growth in Portugal: evidence from causality and cointegration analysis", Economic Modelling, vol. 18, pp. 613-623.

[48] Rodrigues, P.M.M. and A.M.R. Taylor (2007) Efficient tests of the seasonal unit root hypothesis, Journal of Econometrics, 141, 548-573. 
[49] Sargan J.D. and A. Bhargava (1983) Testing for residuals from least squares regression being generated by gaussian random walk, Econometrica, 51, 153-157.

[50] Stock J.H. (1999) A class of tests for integration and cointegration, in Engle R.F. and H. White (eds) Cointegration, Causality and Forecasting: A Festchrift in Honour of Clive W.F. Granger. Oxford University Press. 
Table 1

Test for the null of not periodicity in (4) and of Periodic Integration.

\begin{tabular}{|c|c|c|c|c|c|c|c|}
\hline & & $F_{p e r}$ & $L R_{P I}$ & $P A R$ order & $M S B_{P I}^{b}$ & $M S B_{P I}^{q}$ & $V R T_{P I}$ \\
\hline \multirow[t]{3}{*}{ Australia } & $\ln (\exp / g d p)$ & $6.9374^{* *}$ & $12.6438^{* *}$ & 2 & 0.2798 & 0.2825 & 0.0600 \\
\hline & $\ln (\mathrm{imp} / \mathrm{gdp})$ & $11.2127^{* *}$ & 7.1483 & 1 & 0.3329 & 0.3462 & 0.0618 \\
\hline & difln & 1.8039 & $18.7643^{* *}$ & 3 & $0.1817^{* *}$ & $0.1944^{*}$ & $0.0098^{* *}$ \\
\hline \multirow[t]{3}{*}{ Canada } & $\ln (\exp / g d p)$ & $7.0393^{* *}$ & 3.6664 & 2 & 0.4465 & 0.4474 & 0.0797 \\
\hline & $\ln (\mathrm{imp} / g d p)$ & $7.3068^{* *}$ & 3.3667 & 2 & 0.4291 & 0.4283 & 0.0814 \\
\hline & difln & $2.6053^{* *}$ & $13.0961^{* *}$ & 2 & $0.1826^{* *}$ & $0.1792^{* *}$ & $0.0095^{* *}$ \\
\hline \multirow[t]{3}{*}{ Denmark } & $\ln (\exp / g d p)$ & $3.4351^{* *}$ & 6.9169 & 2 & 0.3046 & 0.3077 & 0.0624 \\
\hline & $\ln (i m p / g d p)$ & $3.4995^{* *}$ & $13.5095^{* *}$ & 1 & 0.1981 & 0.2115 & 0.0149 \\
\hline & difln & $3.1794^{* *}$ & $8.1569^{*}$ & 2 & 0.4362 & 0.4385 & 0.0637 \\
\hline \multirow[t]{3}{*}{ Sweden } & $\ln (\exp / g d p)$ & $3.9594^{* *}$ & 3.5997 & 2 & 0.2732 & 0.2675 & 0.0348 \\
\hline & $\ln (i m p / g d p)$ & $3.9580^{* *}$ & 6.2928 & 1 & 0.2523 & 0.2501 & 0.0331 \\
\hline & difln & $5.2382^{* *}$ & 6.7620 & 3 & 0.3021 & 0.3313 & 0.0217 \\
\hline United & $\ln (\exp / g d p)$ & 0.3915 & 5.8637 & 2 & 0.2752 & 0.2635 & 0.0274 \\
\hline \multirow[t]{2}{*}{ Kingdom } & $\ln (i m p / g d p)$ & $2.7003^{* *}$ & $8.6335^{*}$ & 1 & $0.1964^{*}$ & $0.2038^{*}$ & 0.0351 \\
\hline & difln & $3.7082^{* *}$ & $15.3947^{* *}$ & 1 & $0.1555^{*}$ & $0.1591^{* *}$ & $0.0115^{*}$ \\
\hline \multirow[t]{3}{*}{ Norway } & $\ln (\exp / g d p)$ & 1.5214 & 6.4674 & 2 & $0.1928^{*}$ & $0.1944^{*}$ & 0.0382 \\
\hline & $\ln (i m p / g d p)$ & $3.0904^{* *}$ & 4.7313 & 2 & 0.2746 & 0.2721 & 0.0655 \\
\hline & difln & $2.4200^{* *}$ & 3.3746 & 3 & 0.2762 & 0.2785 & 0.0670 \\
\hline \multirow[t]{3}{*}{ Switzerland } & $\ln (\exp / g d p)$ & $4.6170^{* *}$ & 1.1163 & 2 & 0.2329 & 0.2342 & $0.0111^{*}$ \\
\hline & $\ln (i m p / g d p)$ & 0.7261 & 4.0753 & 2 & $0.2037^{*}$ & $0.2031^{*}$ & $0.0085^{* *}$ \\
\hline & difln & $6.2268^{* *}$ & 1.9552 & 2 & 0.2381 & 0.2330 & $0.0124^{*}$ \\
\hline \multirow[t]{3}{*}{ Japan } & $\ln (\exp / g d p)$ & $2.8044^{* *}$ & 2.9987 & 1 & 0.3039 & 0.3022 & 0.0248 \\
\hline & $\ln (i m p / g d p)$ & 0.2432 & 3.2508 & 1 & 0.3208 & 0.3159 & 0.0255 \\
\hline & difln & 1.0003 & $8.1958^{*}$ & 1 & 0.2420 & 0.2418 & 0.0173 \\
\hline
\end{tabular}


Table 2

Coefficients of (5) and results of the $L R_{C R}$ tests

\begin{tabular}{|c|c|c|c|c|c|c|}
\hline & & \multicolumn{4}{|l|}{} & \\
\hline & & $\hat{\varphi}_{1}$ & $\hat{\varphi}_{2}$ & $\hat{\varphi}_{3}$ & $\hat{\varphi}_{4}$ & $L_{C R}$ \\
\hline Australia & $\ln (\exp / g d p)$ & 0.713 & 1.006 & 1.251 & 1.115 & $33.1368^{* *}$ \\
\hline & $\ln (i m p / g d p)$ & 0.758 & 1.062 & 1.098 & 1.132 & \\
\hline Canada & $\ln (\exp / g d p)$ & 1.1376 & 0.8967 & 1.0797 & 0.908 & $29.5145^{* *}$ \\
\hline & $\ln (i m p / g d p)$ & 1.0770 & 0.8723 & 1.2030 & 0.8848 & \\
\hline Denmark & $\ln (\exp / g d p)$ & 0.9613 & 0.9996 & 1.3155 & 0.7911 & 7.8410 \\
\hline & $\ln (i m p / g d p)$ & 1.3120 & 0.8743 & 1.0011 & 0.8708 & \\
\hline Sweden & $\ln (\exp / g d p)$ & 1.0823 & 0.9574 & 1.2000 & 0.8042 & 6.8975 \\
\hline & $\ln (i m p / g d p)$ & 1.1039 & 0.9999 & 1.1213 & 0.8036 & \\
\hline UK & $\ln (\exp / g d p)$ & 0.9578 & 1.0768 & 1.0082 & 0.9617 & $15.4674^{* *}$ \\
\hline & $\ln (i m p / g d p)$ & 0.9077 & 1.1893 & 0.9651 & 0.9598 & \\
\hline Norway & $\ln (\exp / g d p)$ & 1.0272 & 0.8724 & 1.3097 & 0.8520 & $9.5170^{*}$ \\
\hline & $\ln (i m p / g d p)$ & 0.9821 & 0.9804 & 0.7535 & 1.3784 & \\
\hline Switzerland & $\ln (\exp / g d p)$ & 1.2062 & 1.0615 & 1.1387 & 0.8190 & 1.7272 \\
\hline & $\ln (i m p / g d p)$ & 1.1041 & 1.0119 & 1.0928 & 0.6859 & \\
\hline Japan & $\ln (\exp / g d p)$ & 0.9054 & 1.1573 & 0.9961 & 0.9582 & $12.1204^{* *}$ \\
\hline & $\ln (i m p / g d p)$ & 0.9786 & 1.0267 & 1.0125 & 0.9831 & \\
\hline
\end{tabular}

** and ${ }^{*}$ statistically significant at a $5 \%$ and $10 \%$ respectively. 
Figure 1: Evolution of $\ln (\exp / g d p)$ and $\ln (i m p / g d p)$ for Australia, Canada, Denmark and Sweden.
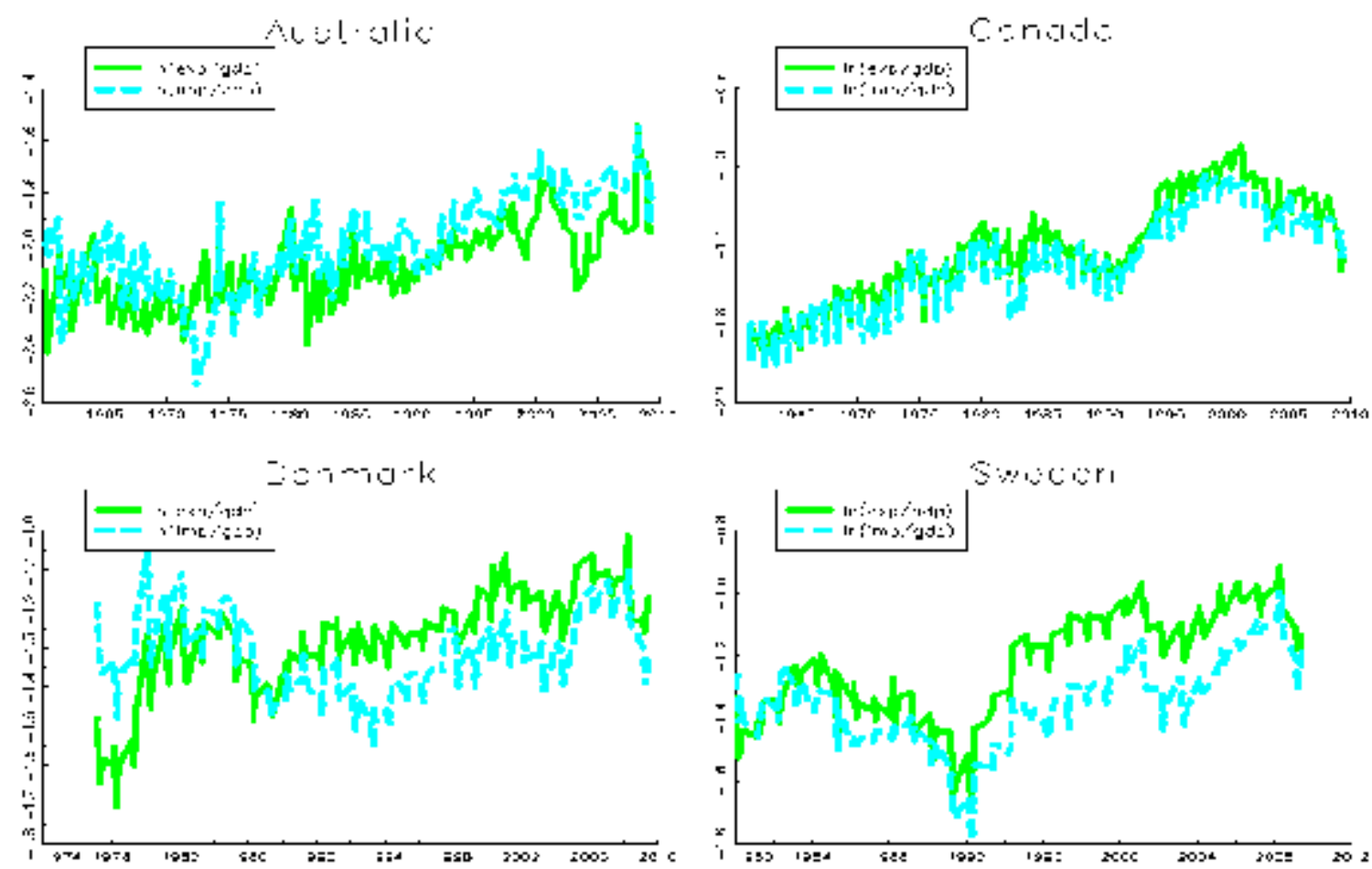
Figure 2: Evolution of $\ln (\exp / g d p)$ and $\ln (i m p / g d p)$ for United Kingdom, Norway, Switzerland and Japan.
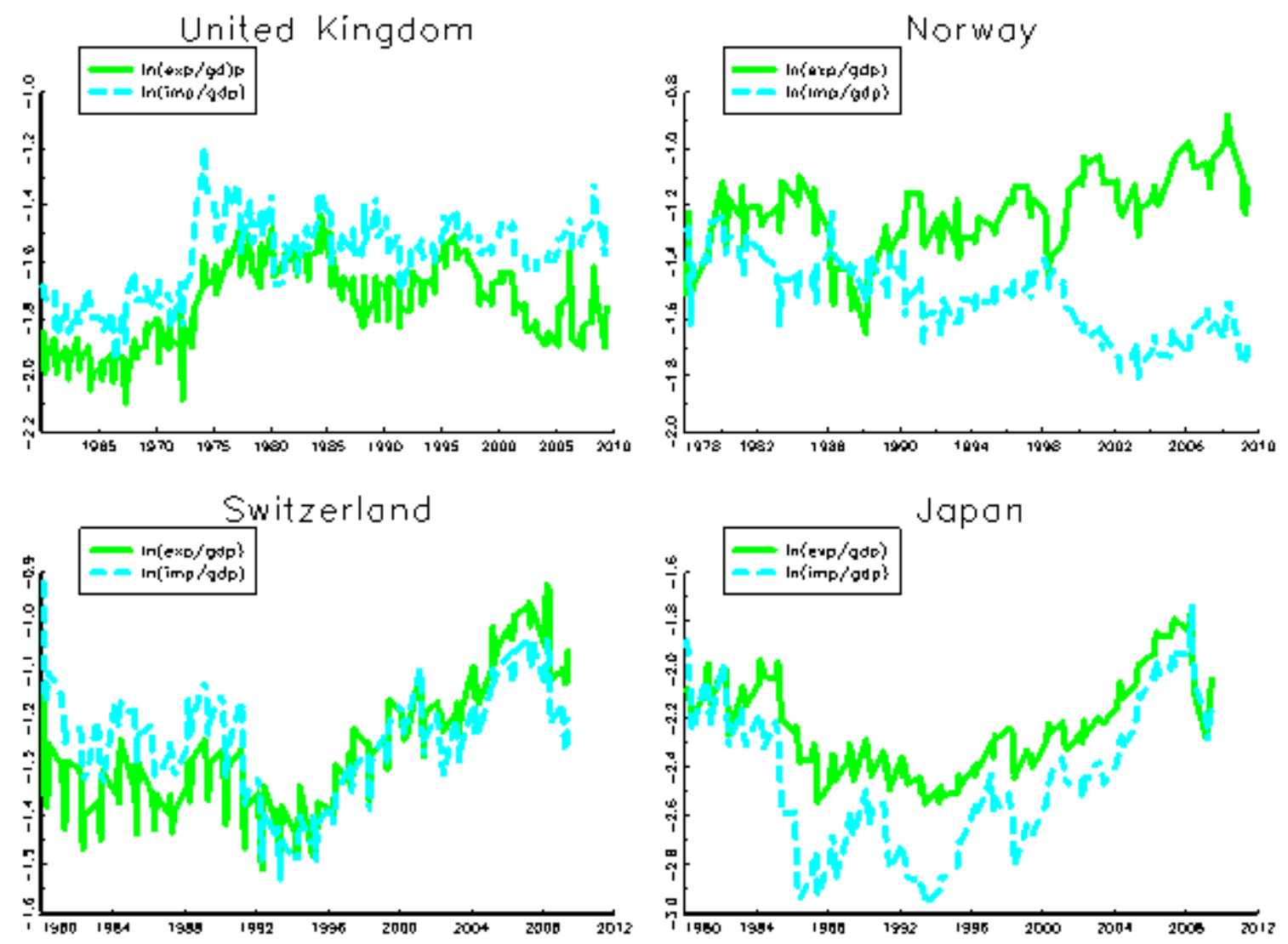